\title{
Increased symptoms of stiffness 1 year after total knee arthroplasty are associated with a worse functional outcome and lower rate of patient satisfaction
}

\author{
N. D. Clement ${ }^{1} \cdot$ M. Bardgett ${ }^{1} \cdot$ D. Weir ${ }^{1} \cdot$ J. Holland ${ }^{1} \cdot$ D. J. Deehan ${ }^{1}$
}

Received: 4 February 2018 / Accepted: 4 May 2018 / Published online: 10 May 2018

(c) The Author(s) 2018

\begin{abstract}
Purpose Symptoms of stiffness after total knee arthroplasty (TKA) cause significant morbidity, but there is limited data to facilitate identification of those most at risk after surgery. Stratifying risk can aid earlier directed treatment options.

Methods A retrospective cohort consisting of 2589 patients undergoing a primary TKA was identified from an established arthroplasty database. Patient demographics, Western Ontario and McMaster Universities Osteoarthritis Index (WOMAC), and short form (SF) 12 scores were collected pre-operatively and 1 year post-operatively. In addition, patient satisfaction was assessed for 1 year. Patients with a worse WOMAC stiffness score in 1 year were defined as the "increased" stiffness group and the other cohort as the non-stiffness group.

Results At 1 year after surgery $129(5 \%)$ patients had a significant increase in their stiffness symptoms (20\%, 95\% confidence interval (CI) 17.9-22.0, $p<0.001$ ), and had significantly (all $p<0.001$ ) less of an improvement in their pain, function and total WOMAC scores, and SF-12 scores compared to the non-stiffness group $(n=2460)$. Patient satisfaction was significantly lower (odds ratio (OR) 0.178 , CI 0.121 to $0.262, p<0.001$ ) for the increased stiffness group. Logistic regression analysis identified male gender (OR 1.66, $p=0.02$ ), lung disease (OR 2.06, $p=0.002$ ), diabetes (OR 1.82, $p=0.02$ ), back pain (OR $1.81, p=0.005$ ), and a pre-operative stiffness score of 44 or more (OR 5.79, $p<0.001$ ) were significantly predictive of increased stiffness.

Conclusion Patients with increased symptoms of stiffness after TKA have a worse functional outcome and a lower rate of patient satisfaction, and patients at risk of being in this group should be informed pre-operatively.

Level of evidence Retrospective prognostic study, Level III.
\end{abstract}

Keywords Total knee arthroplasty $\cdot$ Knee replacement $\cdot$ TKA $\cdot$ Predictors $\cdot$ Stiffness $\cdot$ Outcome

\section{Introduction}

Total knee arthroplasty (TKA) for the treatment of end stage osteoarthritis of the knee has a patient satisfaction rate of between $80 \%$ and $90 \%$ [2]. Persistent pain and functional limitations after TKA are associated with a lower rate of patient satisfaction [12]. It is recognized that reported symptoms of stiffness, failing to squat and kneel, after surgery results in a poor outcome for the patient [17]. Approximated five percent of patients suffer stiffness as a significant

D. J. Deehan

deehan1@hotmail.co.uk

1 Department of Orthopaedics, Freeman Hospital, Freeman Road, High Heaton, Newcastle upon Tyne NE7 7DD, UK complication after their TKA [6], and some require manipulation under anaesthesia [22] or revision surgery because of persistent stiffness [18]. Stiffness after knee arthroplasty may have a genetic component and epidemiological studies have found chromosomal changes in those reporting such symptoms [14], with an increased understanding of the biological basis for such a host response [16]. This is leading to a greater awareness that stiffness is potentially avoidable both from a mechanical and biological perspective [6].

The Western Ontario and McMaster Universities Osteoarthritis Index (WOMAC) [3] assesses the dimensions of pain, stiffness and function (either separately or as an overall index) [29]. The stiffness component of the WOMAC score could be used to measure patient-reported stiffness after TKA, and it has recently been demonstrated to be predictive of post-operative satisfaction [24]. 
The primary aim of this study was to compare the outcome (WOMAC, Short form (SF-) 12, and satisfaction) of patients with increased symptoms of stiffness 1 year after TKA with those who had no change or improvement in symptoms. The secondary aim was to identify independent predictors of increased symptoms of stiffness 1 year following TKA. The novel hypothesis is that patients with increased symptoms of stiffness have a worse outcome, and identification of independent predictors of this group would allow targeted intervention to potentially avoid increased stiffness post-operatively and improve their outcome.

\section{Materials and methods}

Patients for this study were identified retrospectively from a prospectively compiled arthroplasty database held at the study centre. During a 12 year period (2003-2015) 3641 patients undergoing primary TKA at the study centre were asked to complete a pre-operative patient questionnaire. Only patients with primary osteoarthritis were included. Patients who underwent simultaneous bilateral TKA during the study period were excluded $(n=41)$ and for those patients that underwent a second TKA, after the index procedure, only the outcome of the first knee was used for analysis $(n=460)$. Patients who had a deep infection, did not complete the outcome assessments $(n=185)$, or were revised $(n=37)$ at before 1 year follow-up were also excluded from analysis. There were 2589 TKA performed during the study period with complete pre and post-operative data that met the inclusion criteria (Fig. 1). There were 1187 male patients and 1402 female patients, with a mean age of 68.9 (SD 9.7) years.

The WOMAC [3] used in this study was the Likert version 3.1 standardized with English for a British population, consisting of 24 self-administrated questions that were answered for each item on a 5-point Likert scale (none, mild, moderate, severe and extreme). It was reported as three separate subscales: pain, physical function, and stiffness. The WOMAC pain subscale had five questions scored 0 to 4 and was considered invalid if more than one item was missing; hence, it had a range of 0 (no pain) to 20 (maximal pain). In the event of a missing item, the remaining four items were averaged and then multiplied by five [5]. The WOMAC function subscale has 17 questions scored $0-4$ and was considered invalid if more than three items were missing. It had a range of 0 (maximal function) to 68 (minimal function). In the event of missing items, the remaining items were averaged and then multiplied by 17 . The WOMAC stiffness subscale had two items scored $0-4$ and was considered invalid if either was missing; hence it had a range from 0 (no stiffness) to 8 (maximal stiffness). According to recent

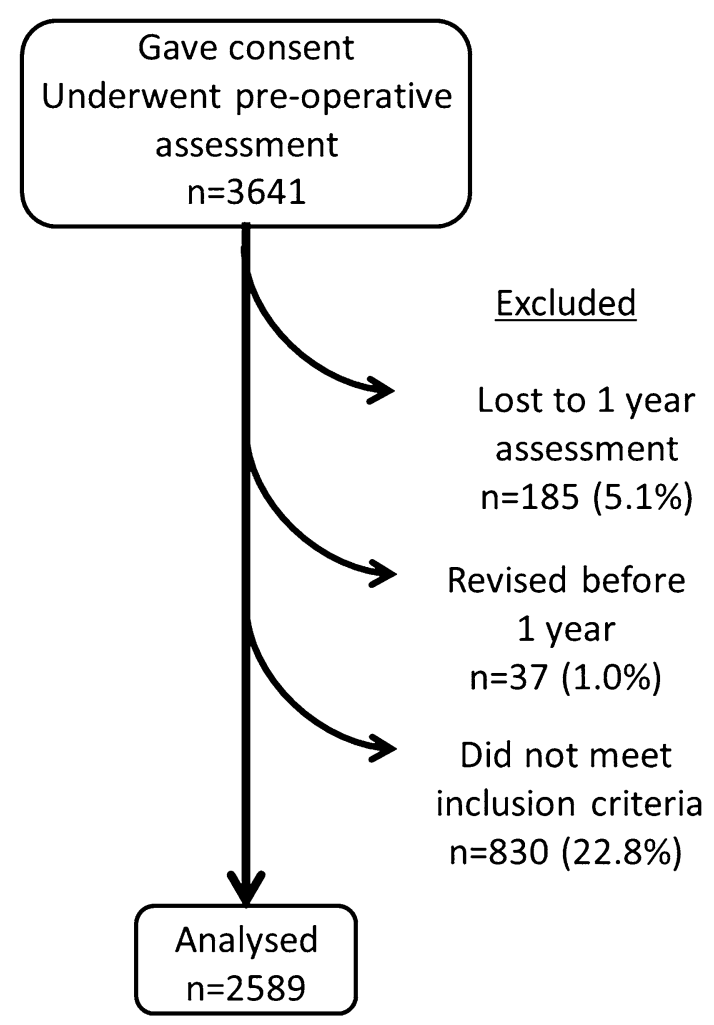

Fig. 1 Flow diagram for the study cohort

recommendations converted the score to a percentage where 0 is the worst and 100 is the best [19].

The Short Form (SF-) 12 is a generic assessment tool to measure a patients wellbeing, which is assessed using a physical component summary (PCS) and a mental component summary (MCS) [25]. Both the SF-12 PCS and MCS range from 0 (worst level of functioning) to 100 (best level of functioning).

Patient satisfaction was assessed by asking the question "How satisfied are you with the results of your knee replacement surgery?" at 1 year following surgery. The response was recorded using a four point Likert scale: very satisfied, somewhat satisfied, somewhat dissatisfied, and very dissatisfied. Patients who recorded very or somewhat satisfied were classified as satisfied.

Patients who had a worse or negative (1 year-pre-operative) change in the WOMAC stiffness score were defined as the increased symptoms of stiffness group. This group with increased symptoms of stiffness were compared to those who had no change or improved symptoms at 1 year. Patients that had no change or an improvement in their stiffness symptoms were used as the comparative subgroup who did not report worsened stiffness as a symptom.

The Freeman Joint Registry is an institutional audit registered with the Newcastle upon Tyne Hospitals NHS Foundation Trust since 2003 (Caldicott@nuth.nhs.uk, Audit Ref: 
3290) (Patients provide written consent to participate in the audit for which patients complete patient-reported outcomes before and at multiple time points following surgery. The collection and use of audit data is approved by the Trusts Caldicott Guardian Mr A Welch (Caldicott ID:2840) at Caldicott@nuth.nhs.uk.

\section{Statistical analysis}

Statistical analysis was performed using Statistical Package for Social Sciences version 17.0 (SPSS Inc., Chicago, IL, USA). The data assessed demonstrated a normal distribution and parametric tests were used to assess continuous variables for significant differences between groups. A Student's $t$ test, unpaired and paired were used to compare linear variables between groups. Dichotomous variables were assessed using a Chi-square test. Receiver operating characteristic (ROC) curve analysis was used to identify thresholds (cut points) in linear variables that were significantly different between the groups. The area under the ROC curve ranges from 0.5 , indicating a test with no accuracy, to 1.0 where the test is perfectly accurate by identifying all satisfied patients. The threshold is equivalent to the point (WOMAC score) at which the sensitivity and specificity are maximal in predicting patient satisfaction [9]. Multivariate logistic regression analyses were used to identify independent predictors of increased symptoms of stiffness at 1 year. A $p$ value of $<0.05$ was defined as statistically significant.

A post hoc power calculation was performed using the WOMAC as the primary outcome. Using the defined minimal clinically important difference in the WOMAC of 15 points [8], a standard deviation (SD) of 26.5, an alpha 0.05 with 129 in the increased stiffness group and 2460 in the control group this offered a power of $100 \%$.

\section{Results}

One year following TKA 129 (5\%) patients had an increase in their symptoms of stiffness, with a mean decrease (worse) of 20.0 [95\% confidence intervals (CI) 17.9-22.0] points in the WOMAC stiffness score relative to their preoperative score.

Both groups had a statistically significant improvement in the components and total WOMAC scores and the SF-12 PCS and MCS, except for the WOMAC stiffness component which deteriorated for the increased stiffness group (Table 1). Despite significant increases in all outcomes measured in the increased stiffness group, other than the stiffness WOMAC score, the non-stiffness group

Table 1 Post-operative outcome measures and the difference relative to pre-operative scores for the all patients according to group

\begin{tabular}{|c|c|c|c|c|c|c|c|}
\hline \multicolumn{2}{|c|}{ Functional Measure } & \multicolumn{2}{|l|}{ Increased Stiffness } & \multirow[t]{2}{*}{ Difference } & \multicolumn{2}{|l|}{$95 \% \mathrm{CI}$} & \multirow[t]{2}{*}{$p$ value* } \\
\hline & & Yes $(n=129)$ & No $(n=2460)$ & & Lower & Upper & \\
\hline \multicolumn{8}{|l|}{ WOMAC } \\
\hline \multirow[t]{3}{*}{ Total } & 1 year & $55.8(22.4)$ & $75.7(19.5)$ & 20.0 & 16.5 & 23.4 & $<0.001$ \\
\hline & Change $(95 \% \mathrm{CI})$ & $9.8(6.9$ to 12.7$)$ & 39.7 (38.9 to 40.5$)$ & 29.9 & 26.4 & 33.4 & $<0.001$ \\
\hline & $p$ value $* *$ & $<0.001$ & $<0.001$ & & & & \\
\hline \multirow[t]{3}{*}{ Pain } & 1 year & $63.1(24.0)$ & $81.0(19.8)$ & 18.0 & 14.4 & 21.5 & $<0.001$ \\
\hline & Change (95\% CI) & 20.7 (16.9 to 24.5$)$ & $46.0(45.1$ to 46.8$)$ & 25.2 & 21.3 & 29.2 & $<0.001$ \\
\hline & $p$ value $* *$ & $<0.001$ & $<0.001$ & & & & \\
\hline \multirow[t]{3}{*}{ Function } & 1 year & $55.4(23.6)$ & $74.5(20.7)$ & 19.1 & 15.4 & 22.8 & $<0.001$ \\
\hline & Change (95\% CI) & 10.1 (6.9 to 13.3$)$ & $38.2(37.4$ to 39.0$)$ & 28.1 & 24.2 & 31.7 & $<0.001$ \\
\hline & $p$ value $* *$ & $<0.001$ & $<0.001$ & & & & \\
\hline \multirow[t]{3}{*}{ Stiffness } & 1 year & $41.0(22.4)$ & $73.2(21.3)$ & 32.3 & 28.5 & 36.0 & $<0.001$ \\
\hline & Change $(95 \% \mathrm{CI})$ & $-20.0(17.9$ to 22.0$)$ & 37.3 (36.4 to 38.2$)$ & 57.2 & 53.1 & 61.3 & $<0.001$ \\
\hline & $p$ value $* *$ & $<0.001$ & $<0.001$ & & & & \\
\hline \multicolumn{8}{|l|}{ SF-12 } \\
\hline \multirow[t]{3}{*}{ PCS } & 1 year & $31.8(8.8)$ & $37.9(11.1)$ & 6.1 & 4.2 & 8.1 & $<0.001$ \\
\hline & Change $(95 \% \mathrm{CI})$ & $3.4(1.8$ to 5.0$)$ & $10.3(9.9$ to 10.7$)$ & 6.9 & 5.1 & 8.8 & $<0.001$ \\
\hline & $p$ value $* *$ & $<0.001$ & $<0.001$ & & & & \\
\hline \multirow[t]{3}{*}{ MCS } & 1 year & $44.0(14.7)$ & $49.5(12.7)$ & 5.5 & 3.2 & 7.8 & $<0.001$ \\
\hline & Change (95\% CI) & $-2.2(-0.1$ to -4.4$)$ & 2.4 (1.9 to 2.9$)$ & 4.7 & 2.5 & 6.9 & $<0.001$ \\
\hline & $p$ value** & 0.04 & $<0.001$ & & & & \\
\hline
\end{tabular}

$* t$ test

**Paired $t$ test 
had a significant greater improvement. The non-stiffness group enjoyed an approximate $40 \%$ improvement in all of the components and total WOMAC scores, whereas the increased stiffness group had at best a $21 \%$ improvement in pain and at worst a $20 \%$ worsening in the stiffness component (Fig. 2). Patient satisfaction was significantly lower (odds ratio (OR) $0.178,95 \%$ CI 0.121 to $0.262, p<0.001$ ) for the increased stiffness group $(n=83,64.3 \%)$ when compared to the control group ( $n=2229,91.0 \%)$.

Univariate analysis identified pre-operative factors that were predictive of increased symptoms of stiffness at 1 year (Table 2). ROC curve analysis was used to identify threshold values in the linear variables that were demonstrated to be significantly different between the groups (Table 2). The most reliable predictor of increased stiffness at 1 year was the pre-operative WOMAC stiffness score (Fig. 3) (Table 3). Interestingly pain, function, and the total WOMAC scores were poor predictors, with an AUC of less than 0.7. The threshold values were used as dichotomous variables as predictors in the regression models. Logistic regression analysis identified male gender $(p=0.017)$, lung disease $(p=0.002)$, diabetes $(p=0.02)$, back pain $(p=0.005)$, and a pre-operative stiffness score of 44 or more $(p<0.001)$ were significantly predictive of increased stiffness 1 year following surgery (Table 4$)$.

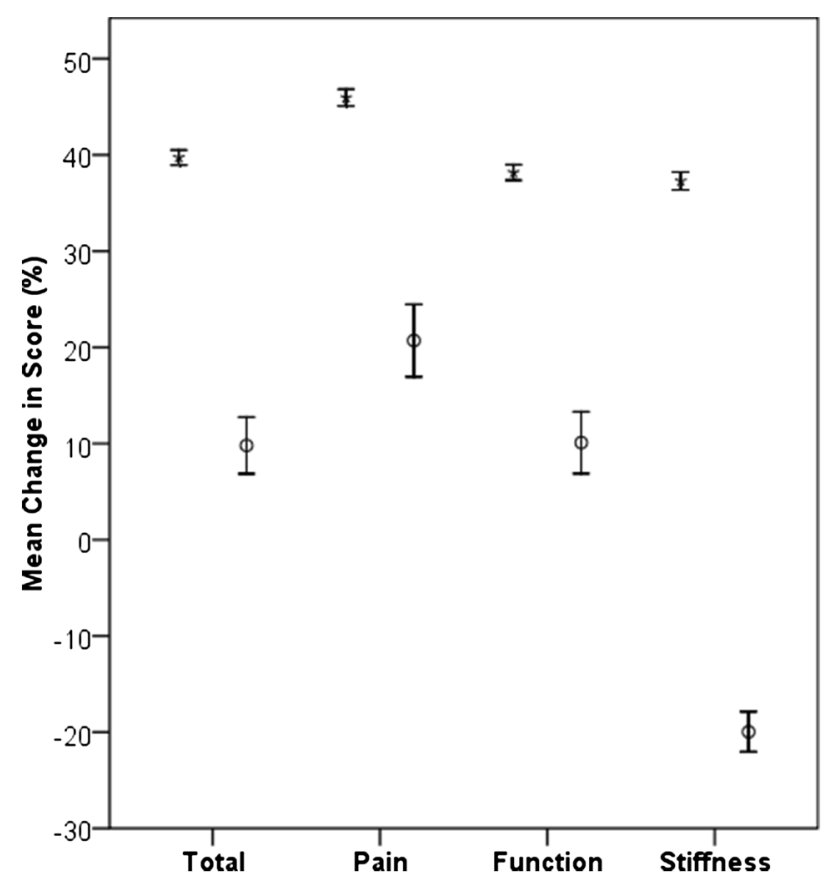

Fig. 2 Mean change in the components and total WOMAC for those with increased stiffness (circles) and the control (star) groups. Error bars represent $95 \%$ confidence intervals

\section{Discussion}

The important findings of the study were that patients with subjectively increase symptoms of stiffness have a worse functional outcome and a lower rate of post-operative satisfaction, and that male gender, lung disease, diabetes, back pain, and a pre-operative WOMAC stiffness score of 44 or more were predictive of this group.

Arthrofibrosis is a significant complication following TKA, which is reported to have an incidence of between 1 and $13 \%$ [6]. Post-operative fibrosis of the knee is defined as a limited range of movement (in flexion and/or extension), that is not attributable to specific cause, but due to soft-tissue fibrosis that was not present pre-operatively [13]. The current study assessed symptoms of stiffness as defined by the patient using the WOMAC score and this may not relate to a limited range of movement and a secondary cause was not ruled out. Loss of motion may be predictable after knee arthroplasty, but such objective findings may not necessarily relate to symptoms of stiffness [15]. Stiffness may correlate with other symptoms, but not necessarily key components of function and as such could be regarded as a distinct entity within the complex of reported measures of outcome [26, 27].

Fulfilment of patient expectations after TKA is associated with a greater rate of satisfaction [17]. Approximately $60 \%$ of patients expect to kneel and 50\% expect to squat after their TKA surgery, but the likelihood of these being fulfilled at 1 year is approximately $15 \%$ and $25 \%$, respectively [7]. When these expectations are not achieved the likelihood of the patient being dissatisfied is significantly increased (OR of 8 and 9, respectively) [7]. The risk factors in the current study could be used to identify patients at risk of increased stiffness who may then benefit from expectation modification that may improve their satisfaction.

It is interesting that lung disease, diabetes, and back pain were independent predictors of increased stiffness after TKA, as all have been associated with fibrotic or inflammatory pathologies previously. Chronic lung disease is associated with pulmonary fibrosis and this may explain why such patients are at risk of increased stiffness after TKA; the association has previously suggested [1]. Diabetes is a recognised comorbidity associated with a worse functional outcome [4] and stiffness [10] after TKA, which supports the findings of the current study. Nonspecific lower lumbar back pain has recently been demonstrated to be directly related to increased lumber stiffness [28], and although there is no link with a fibrotic condition there is an accepted inflammatory element which may be associated with the aetiology of knee stiffness [23].

A pre-operative WOMAC stiffness score of 44 or more was a significant predictor of increased symptoms of 
Table 2 Patient demographics and pre-operative functional scores according to symptoms of stiffness 1 year after surgery

\begin{tabular}{|c|c|c|c|c|c|c|c|}
\hline \multirow[t]{2}{*}{ Demographic } & \multirow{2}{*}{ Descriptive } & \multicolumn{2}{|c|}{ Increased Stiffness } & \multirow{2}{*}{$\begin{array}{l}\text { Odds } \\
\text { ratio/difference }\end{array}$} & \multicolumn{2}{|c|}{$95 \% \mathrm{CI}$} & \multirow[t]{2}{*}{$p$ value } \\
\hline & & Yes $(n=129)$ & No $(n=2460)$ & & Lower & Upper & \\
\hline \multirow[t]{2}{*}{ Gender ( $n, \%$ of group) } & Male & $78(60.4)$ & $1109(45.1)$ & 1.86 & 1.30 & 2.68 & 0.001 \\
\hline & Female & $51(39.5)$ & $1351(54.9)$ & & & & \\
\hline Mean age (years: mean, SD) & & $69.7(9.6)$ & $68.8(9.7)$ & 0.9 & -2.6 & 8.7 & n.s \\
\hline BMI (kg/m²: mean, SD) & & $29.1(5.0)$ & $29.8(6.9)$ & 0.7 & -0.6 & 1.9 & n.s \\
\hline \multirow[t]{12}{*}{ Comorbidity ( $n, \%$ of group) } & Heart disease & $21(16.3)$ & $414(16.8)$ & 0.96 & 0.60 & 1.55 & n.s \\
\hline & Hypertension & $66(51.2)$ & $1346(54.7)$ & 0.87 & 0.61 & 1.24 & n.s \\
\hline & Lung disease & $33(25.6)$ & $366(14.9)$ & 1.97 & 1.30 & 2.97 & 0.001 \\
\hline & Cancer & $8(6.2)$ & $117(4.8)$ & 1.32 & 0.63 & 2.77 & n.s \\
\hline & Neurological disease & $14(10.9)$ & $139(5.7)$ & 2.03 & 1.14 & 3.63 & 0.02 \\
\hline & Diabetes mellitus & $27(20.9)$ & 338 (13.7) & 1.66 & 1.07 & 2.58 & 0.02 \\
\hline & Gastric ulceration & $18(14.0)$ & 309 (12.6) & 1.13 & 0.68 & 1.88 & n.s \\
\hline & Kidney disease & $8(6.2)$ & $71(2.9)$ & 2.23 & 1.05 & 4.73 & 0.03 \\
\hline & Liver disease & $5(3.9)$ & $39(1.6)$ & 2.50 & 1.0 & 6.46 & 0.05 \\
\hline & Anaemia & $9(7.0)$ & $237(9.6)$ & 0.70 & 0.35 & 1.40 & n.s \\
\hline & Depression & $28(21.7)$ & $348(14.1)$ & 1.68 & 1.09 & 2.60 & 0.02 \\
\hline & Back pain & $76(58.9)$ & $1233(50.1)$ & 1.43 & 1.0 & 2.0 & n.s \\
\hline \multicolumn{8}{|c|}{ Functional measures (mean, SD) } \\
\hline \multirow[t]{4}{*}{ WOMAC } & Total & $46.0(16.1)$ & $36.0(16.2)$ & 10.0 & 7.1 & 12.8 & $<0.001$ \\
\hline & Pain & $42.4(15.9)$ & $35.1(17.7)$ & 7.3 & 4.2 & 10.4 & $<0.001$ \\
\hline & Function & $45.3(16.9)$ & $36.3(16.9)$ & 9.0 & 6.0 & 12.0 & $<0.001$ \\
\hline & Stiffness & $61.0(22.4)$ & $36.0(19.6)$ & 25.0 & 21.5 & 28.5 & $<0.001$ \\
\hline \multirow[t]{2}{*}{ SF-12 } & PCS & $28.4(7.6)$ & $27.5(7.4)$ & 0.8 & -0.5 & 2.2 & n.s \\
\hline & MCS & $46.3(13.3)$ & $47.1(13.6)$ & 0.8 & -1.6 & 3.2 & n.s \\
\hline
\end{tabular}

n.s. non-significant

*Unpaired $t$ test unless otherwise stated

**Chi-square

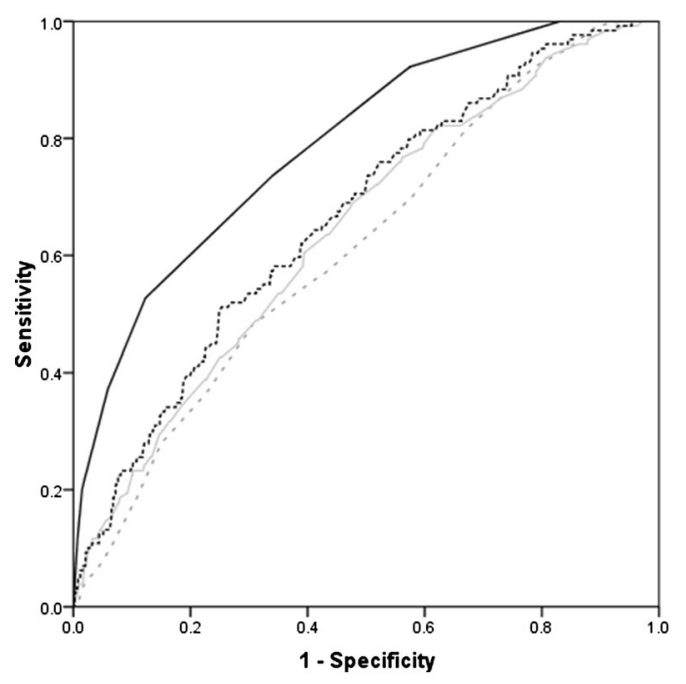

WOMAC

Fig. 3 ROC curve for predicting increased stiffness 1 year after surgery using the pre-operative components and total WOMAC score stiffness 1 year following TKA, and was demonstrated to be reliable with a AUC of 0.8. This score could be used as a screening tool, being composed of only two questions it would be simple to assess. This combined with the other risk factors identified could be used to identify an "at risk group" pre-operatively, who may benefit from peri-operative interventions or at least made aware during the consent process that they are at risk of increased symptoms of stiffness and are less likely to be satisfied. There are multiple post-operative interventions suggested to prevent stiffness from occurring [6]. However, with greater understanding of fibrosis pathways there may be inhibitors that may stop the post-operative stiffness from developing [1], which may improve the patients functional outcome and satisfaction.

The major limitation of this study was the retrospective design that did not enable range of movement data to be assessed. Recording the range of movement pre- and post-operatively would have been desirable as this could have been correlated with the patient's assessment of their stiffness. Surgeons often define knee stiffness as limitation 
Table 3 ROC curve analysis identifying the threshold value for the components and the total WOMAC scores that predict increased stiffness at 1 year

Table 4 Patient demographics that are independent predictors of increased symptoms of stiffness after TKR using bivariate regression analysis

\begin{tabular}{llllllll}
\hline WOMAC & $\begin{array}{l}\text { Threshold } \\
\text { value }\end{array}$ & Sensitivity & Specificity & AUC & \multicolumn{2}{l}{$95 \%$ CI } & $p$ value \\
\cline { 6 - 7 } & & & & & Lower & Lower & \\
\hline Total & 40 & 61.2 & 61.2 & 0.666 & 0.620 & 0.712 & $<0.001$ \\
Pain & 36 & 56.6 & 57.8 & 0.616 & 0.569 & 0.663 & $<0.001$ \\
Function & 40 & 60.5 & 60.5 & 0.643 & 0.596 & 0.690 & $<0.001$ \\
Stiffness & 44 & 73.6 & 66.0 & 0.790 & 0.751 & 0.829 & $<0.001$ \\
\hline
\end{tabular}

\begin{tabular}{|c|c|c|c|c|c|c|}
\hline \multirow{3}{*}{$\begin{array}{l}\text { Demographic } \\
\text { Gender }\end{array}$} & \multirow[t]{2}{*}{ Descriptive } & & \multirow[t]{2}{*}{ OR } & \multicolumn{2}{|c|}{$95 \% \mathrm{CI}$} & \multirow[t]{3}{*}{$p$ value } \\
\hline & & & & Lower & Upper & \\
\hline & \multicolumn{2}{|l|}{ Male } & \multicolumn{3}{|l|}{ Reference } & \\
\hline & Female & & 0.604 & 0.398 & 0.915 & 0.017 \\
\hline \multicolumn{3}{|l|}{ Mean age } & 1.0 & 0.978 & 1.022 & n.s \\
\hline \multicolumn{3}{|l|}{ BMI } & 0.983 & 0.941 & 1.026 & n.s \\
\hline \multirow[t]{13}{*}{ Comorbidity } & \multicolumn{2}{|l|}{ Not present } & Reference & & & \\
\hline & \multicolumn{2}{|l|}{ Heart disease } & 0.669 & 0.390 & 1.147 & n.s \\
\hline & \multicolumn{2}{|l|}{ Hypertension } & 0.788 & 0.524 & 1.184 & n.s \\
\hline & \multicolumn{2}{|l|}{ Lung disease } & 2.064 & 1.299 & 3.279 & 0.002 \\
\hline & \multicolumn{2}{|l|}{ Cancer } & 1.086 & 0.478 & 2.469 & n.s \\
\hline & \multicolumn{2}{|l|}{ Neurological disease } & 1.684 & 0.852 & 3.329 & n.s \\
\hline & \multicolumn{2}{|l|}{ Diabetes mellitus } & 1.815 & 1.099 & 2.998 & 0.02 \\
\hline & \multicolumn{2}{|l|}{ Gastric ulceration } & 0.972 & 0.54 & 1.748 & n.s \\
\hline & \multicolumn{2}{|l|}{ Kidney disease } & 1.451 & 0.576 & 3.655 & n.s \\
\hline & \multicolumn{2}{|l|}{ Liver disease } & 2.341 & 0.765 & 7.162 & n.s \\
\hline & \multicolumn{2}{|l|}{ Anaemia } & 0.602 & 0.278 & 1.306 & n.s \\
\hline & \multicolumn{2}{|l|}{ Depression } & 1.499 & 0.863 & 2.603 & n.s \\
\hline & \multicolumn{2}{|l|}{ Back pain } & 1.806 & 1.195 & 2.729 & 0.005 \\
\hline \multicolumn{7}{|c|}{ Functional measure } \\
\hline \multirow[t]{8}{*}{ WOMAC } & \multirow[t]{2}{*}{ Total } & $<40$ & Reference & & & \\
\hline & & $\geq 40$ & 0.816 & 0.3 & 2.222 & n.s \\
\hline & \multirow[t]{2}{*}{ Pain } & $<36$ & Reference & & & \\
\hline & & $\geq 36$ & 0.849 & 0.478 & 1.506 & n.s \\
\hline & \multirow[t]{2}{*}{ Function } & $<40$ & Reference & & & \\
\hline & & $\geq 40$ & 1.942 & 0.81 & 4.654 & n.s \\
\hline & \multirow[t]{2}{*}{ Stiffness } & $<44$ & Reference & & & \\
\hline & & $\geq 44$ & 5.787 & 3.479 & 9.624 & $<0.001$ \\
\hline \multirow[t]{2}{*}{ SF-12 } & \multicolumn{2}{|l|}{ PCS } & 0.974 & 0.945 & 1.003 & n.s \\
\hline & MCS & & 0.987 & 0.97 & 1.003 & n.s \\
\hline
\end{tabular}

All variables from Table 1 and threshold values for the components and total WOMAC score (Table 3) were all entered into the model using "enter" methodology (Nagelkerke $R^{2}=0.17$ )

n.s. non-significant

in the range of motion of the joint [13], but patients may not necessarily define this in the same way [11]. However, it has previously been demonstrated that a significant correlation exists between the flexion, but not extension, and the stiffness component of the WOMAC score [21]. A prospective study would have allowed subgroup assessment of patients with increased symptoms of stiffness to a greater depth than the patient-reported outcome measures used in the current study. Objective and qualitative assessment would have enable the stiffness factor to be assessed using range of movement to confirm the patients impressions or whether this was an expectation mismatch, respectively. Qualitative assessment would have also given insight into why those patients with increased symptoms of stiffness were dissatisfied with their TKA. 
Surgeons should be aware that a proportion of patients will have increased symptoms of stiffness after TKA and that they have a worse functional outcome and a lower rate of post-operative satisfaction. Patients at risk may benefit from increased early physiotherapy or other treatment modalities [20] to prevent an increase in their symptoms of stiffness after TKA.

\section{Conclusion}

Patients with increased symptoms of stiffness after TKA have a worse functional outcome and a lower rate of patient satisfaction, and patients at risk of being in this group should be informed preoperatively.

Funding This research did not receive any specific grant from funding agencies in the public, commercial, or not-for-profit sectors.

\section{Compliance with ethical standards}

Conflict of interest The authors declare that they have no conflict of interest.

Ethical approval NHS Research Ethics committee approval was not required. Appropriate institutional approval was obtained for this study.

Informed consent All patients signed informed consent to be part of the institution's joint replacement registry.

Open Access This article is distributed under the terms of the Creative Commons Attribution 4.0 International License (http://creativeco mmons.org/licenses/by/4.0/), which permits unrestricted use, distribution, and reproduction in any medium, provided you give appropriate credit to the original author(s) and the source, provide a link to the Creative Commons license, and indicate if changes were made.

\section{References}

1. Abdul N, Dixon D, Walker A, Horabin J, Smith N, Weir DJ, Brewster NT, Deehan DJ, Mann DA, Borthwick LA (2015) Fibrosis is a common outcome following total knee arthroplasty. Sci Rep 5:16469

2. Baker PN, van der Meulen JH, Lewsey J, Gregg PJ (2007) The role of pain and function in determining patient satisfaction after total knee replacement. Data from the National Joint Registry for England and Wales. J Bone Jt Surg Br 89:893-900

3. Bellamy N, Buchanan WW, Goldsmith CH, Campbell J, Stitt LW (1988) Validation study of WOMAC: a health status instrument for measuring clinically important patient relevant outcomes to antirheumatic drug therapy in patients with osteoarthritis of the hip or knee. J Rheumatol 15:1833-1840

4. Brock TM, Shirley M, Bardgett M, Walker M, Deehan DJ (2017) Inadequate pre-operative glycaemic control in patients with diabetes mellitus adversely influences functional recovery after total knee arthroplasty: Patients with impaired glycaemic control exhibit poorer functional outcomes at 1-year post-arthroplasty. Knee Surg Sports Traumatol Arthrosc 25:1801-1806
5. Burch FX, Tarro JN, Greenberg JJ, Carroll WJ (2008) Evaluating the benefits of patterned stimulation in the treatment of osteoarthritis of the knee: a multi-center, randomized, single-blind, controlled study with an independent masked evaluator. Osteoarthritis Cartil 16:865-872

6. Cheuy VA, Foran JRH, Paxton RJ, Bade MJ, Zeni JA, StevensLapsley JE (2017) Arthrofibrosis Associated With Total Knee Arthroplasty. J Arthroplasty 32:2604-2611

7. Clement ND, MacDonald D, Patton JT, Burnett R (2015) Postoperative Oxford knee score can be used to indicate whether patient expectations have been achieved after primary total knee arthroplasty. Knee Surg Sports Traumatol Arthrosc 23:1578-1590

8. Escobar A, Quintana JM, Bilbao A, Arostegui I, Lafuente I, Vidaurreta I (2007) Responsiveness and clinically important differences for the WOMAC and SF-36 after total knee replacement. Osteoarthritis Cartil 15:273-280

9. Farrar JT, Young JP Jr, LaMoreaux L, Werth JL, Poole RM (2001) Clinical importance of changes in chronic pain intensity measured on an 11-point numerical pain rating scale. Pain 94:149-158

10. Fisher DA, Dierckman B, Watts MR, Davis K (2007) Looks good but feels bad: factors that contribute to poor results after total knee arthroplasty. J Arthroplasty 22:39-42

11. Halls S, Dures E, Kirwan J, Pollock J, Baker G, Edmunds A, Hewlett $S$ (2015) Stiffness is more than just duration and severity: a qualitative exploration in people with rheumatoid arthritis. Rheumatology 54:615-622

12. Hamilton DF, Lane JV, Gaston P, Patton JT, MacDonald D, Simpson AH, Howie CR (2013) What determines patient satisfaction with surgery? A prospective cohort study of 4709 patients following total joint replacement. BMJ Open 9(4):3

13. Kalson NS, Borthwick LA, Mann DA, Deehan DJ, Lewis P, Mann C, Mont MA, Morgan-Jones R, Oussedik S, Williams FM, Toms A, Argenson JN, Bellemans J, Bhave A, Furnes O, Gollwitzer H, Haddad FS, Hofmann S, Krenn V (2016) International consensus on the definition and classification of fibrosis of the knee joint. Bone Jt J 98-B:1479-1488

14. Kalson NS, Brock TM, Mangino M, Fabiane SM, Mann DA, Borthwick LA, Deehan DJ, Williams FMK (2018) Reduced telomere length is associated with fibrotic joint disease suggesting that impaired telomere repair contributes to joint fibrosis. PLoS One 13:e0190120

15. Malviya A, Lingard EA, Weir DJ, Deehan DJ (2009) Predicting range of movement after knee replacement: the importance of posterior condylar offset and tibial slope. Knee Surg Sports Traumatol Arthrose 17:491-498

16. Paish HL, Kalson NS, Smith GR, Del Carpio PA, Baldock TE, Smith N, Swist-Szulik K, Weir DJ, Bardgett M, Deehan DJ, Mann DA, Borthwick LA (2017) Fibroblasts promote inflammation and pain via IL-1alpha induction of the monocyte chemoattractant chemokine (C-C Motif) Ligand 2. Am J Pathol 188:696-714

17. Scott CE, Bugler KE, Clement ND, MacDonald D, Howie CR, Biant LC (2012) Patient expectations of arthroplasty of the hip and knee. J Bone Joint Surg Br 94:974-981

18. Sharkey PF, Lichstein PM, Shen C, Tokarski AT, Parvizi J (2014) Why are total knee arthroplasties failing today-has anything changed after 10 years? J Arthroplasty 29:1774-1778

19. Singh J, Sloan JA, Johanson NA (2010) Challenges with healthrelated quality of life assessment in arthroplasty patients: problems and solutions. J Am Acad Orthop Surg 18:72-82

20. Smith EB, Shafi KA, Greis AC, Maltenfort MG, Chen AF (2016) Decreased flexion contracture after total knee arthroplasty using Botulinum toxin A: a randomized controlled trial. Knee Surg Sports Traumatol Arthrosc 24:3229-3234

21. Stucki G, Sangha O, Stucki S, Michel BA, Tyndall A, Dick W, Theiler R (1998) Comparison of the WOMAC (Western Ontario 
and McMaster Universities) osteoarthritis index and a self-report format of the self-administered Lequesne-Algofunctional index in patients with knee and hip osteoarthritis. Osteoarthr Cartil 6:79-86

22. Vanlommel L, Luyckx T, Vercruysse G, Bellemans J, Vandenneucker H (2017) Predictors of outcome after manipulation under anaesthesia in patients with a stiff total knee arthroplasty. Knee Surg Sports Traumatol Arthrosc 25:3637-4363

23. Walker BF, Williamson OD (2009) Mechanical or inflammatory low back pain. What are the potential signs symptoms? Man Ther 14:314-320

24. Walker LC, Clement ND, Bardgett M, Weir D, Holland J, Gerrand C, Deehan DJ (2018) The WOMAC score can be reliably used to classify patient satisfaction after total knee arthroplasty. Knee Surg Sports Traumatol Arthrosc. https://doi.org/10.1007/s0016 7-018-4879-5

25. Ware J Jr, Kosinski M, Keller SD (1996) A 12-Item Short-Form Health Survey: construction of scales and preliminary tests of reliability and validity. Med Care 34:220-233
26. Witvrouw E, Victor J, Bellemans J, Rock B, Van LR, Van Der Slikke R, Verdonk R (2002) A correlation study of objective functionality and WOMAC in total knee arthroplasty. Knee Surg Sports Traumatol Arthrosc 10:347-351

27. Wolfe F (1999) Determinants of WOMAC function, pain and stiffness scores: evidence for the role of low back pain, symptom counts, fatigue and depression in osteoarthritis, rheumatoid arthritis and fibromyalgia. Rheumatology 38:355-361

28. Wong AY, Parent EC, Prasad N, Huang C, Chan KM, Kawchuk GN (2016) Does experimental low back pain change posteroanterior lumbar spinal stiffness and trunk muscle activity? A randomized crossover study. Clin Biomech (Bristol Avon) 34:45-52

29. Woolacott NF, Corbett MS, Rice SJ (2012) The use and reporting of WOMAC in the assessment of the benefit of physical therapies for the pain of osteoarthritis of the knee: findings from a systematic review of clinical trials. Rheumatology 51:1440-1446 